Bull. Mater. Sci., Vol. 36, No. 6, November 2013, pp. 1097-1101. (C) Indian Academy of Sciences.

\title{
An efficient method combining thermal annealing and acid leaching for impurities removal from silica intended for photovoltaic application
}

\author{
M KHALIFA ${ }^{\mathrm{a}}$, M HAJJI ${ }^{\mathrm{a}, \mathrm{b} *}$ and H EZZAOUIA ${ }^{\mathrm{a}}$ \\ ${ }^{a}$ Laboratoire de Photovoltaïque, CRTEn, Technopôle de Borj-Cédria, BP 95 CP 2050, Hammam-Lif, Tunisia \\ bInstitut Supérieur d'Electronique et de Communication de Sfax, Route de Tunis Km 10, Cité El Ons, B.P. 1163, 3021, \\ Sfax, Tunisia
}

MS received 23 April 2012; revised 5 June 2012

\begin{abstract}
This work investigates the photothermal treatment of silica sand to reduce impurities to a low level suitable for the production of acceptable solar grade silicon for photovoltaic application. It describes experiment carried out by using a tungsten lamp furnace to purify silica under controlled atmosphere. This process enables to attract impurities to the surface of silica grains where they can be easily extracted by partial dissolution in an acid mixture. Thus obtained silica was investigated by inductively coupled plasma atomic emission spectrometry (ICPAES) method. Major impurities present in silica sand were $\mathrm{Al}, \mathrm{K}, \mathrm{Fe}, \mathrm{Na}, \mathrm{Ca}, \mathrm{Mg}$ and $\mathrm{B}$. Among the new products, almost major impurities were removed effectively. Indeed purity degree, given by characterization of ICP-AES, passes from 99.76 to $99.96 \%$ and the average impurity removal efficiency is $83.33 \%$.
\end{abstract}

Keywords. Silica; acid leaching; thermal annealing; ICP-AES.

\section{Introduction}

Silica is used in various industries. The most important application is its use for silicon production with their different grades: metallurgical grade (MG-Si), solar grade (SG-Si) and electronic grade (EG-Si). All these silicon grades are obtained by thermal reduction of silica in an electric arc furnace followed by several treatments and expensive purification processes depending on the required purity of the final product. Most of SG-Si used for PV applications stems from rejects of EG-Si used in the electronic industry. However, its annual supply is surpassed by its demand, urging the need of novel technological solutions for the production of a relatively low SG-Si. The most interesting route for direct production of low cost SG-Si is the use of silica with high purity. To achieve this goal, an efficient purification process for silica is needed. Many studies were carried out in this field for various purposes and using various techniques. Among these techniques one can cite mainly: the application of power ultrasound to the surface cleaning of silica (Farmer et al 2000), acid leaching (Santos et al 1990; Barret et al 2001; Pires et al 2003; Kheloufi 2009; Lee et al 2009) and reverse flotation technique (Mowla et al 2008).

In this work, we present a new, efficient and low cost procedure for the purification of natural silica. In this technique, silica is subjected to thermal annealing in an infrared furnace followed by acid leaching. Thus obtained silica was

\footnotetext{
*Author for correspondence (mhajji2001@yahoo.fr)
}

investigated by inductively coupled plasma atomic emission spectrometry (ICP-AES) method.

\section{Experimental}

The silica used in this work is a natural one from the region of Siliana in Tunisia. Prior to thermal annealing, silica was dipped in an acid mixture solution, $\mathrm{HCl}: \mathrm{HNO}_{3}$ (AS1) with a volume proportion of $2: 1$ to remove metallic impurities located at the surface of silica grains. Then it was abundantly rinsed with deionized water and dried under vacuum in an oven at a temperature of about $120{ }^{\circ} \mathrm{C}$ (step 0). After this cleaning step, with an aim of removing the undesirable impurities, the silica was thermally annealed in an infrared furnace at a temperature of $1000{ }^{\circ} \mathrm{C}$ under $\mathrm{O}_{2}$ atmosphere. Following rapid thermal processing (RTP), silica is subjected to an acid leaching using an acid mixture solution (AS2) composed of $\mathrm{HF}(5 \%): \mathrm{HCl}(4 \%)$ with a volume fraction of 1:7. During this acid leaching, which was carried out under power ultrasound, an excess of the obtained silica was abundantly dissolved in $10 \mathrm{ml}$ of (AS2) solution for $4 \mathrm{~h}$. Then silica was filtered and dried as described above. To further improve the purity, silica undergoes second and third stages of purification processes following the scheme indicated for the first run until reaching the desired purity (figure 1). ICP-AES was used in analysis of the following impurities: $\mathrm{P}, \mathrm{B}, \mathrm{Fe}, \mathrm{Ca}, \mathrm{K}, \mathrm{Na}, \mathrm{Mg}, \mathrm{Al}, \mathrm{Zn}$, $\mathrm{Ni}, \mathrm{Cu}$ and $\mathrm{Cd}$. The silica samples chosen for investigation were the natural silica after chemical treatment with $c$-aqua regia used as starting material (SM), SM after three successive acid leaching in diluted $\mathrm{HF} / \mathrm{HCl}$ solution and the same 
material after different purification stages composed of thermal annealing followed by acid leaching in the same $\mathrm{HF} / \mathrm{HCl}$ solution.

\section{Results and discussion}

After the cleaning step, silica was analysed by ICP-AES in order to determine the amounts of metallic impurities present in our starting material. The metal contents of the untreated silica are shown in table 1 . The majority of impurities present in the starting silica are $\mathrm{P}(3.49 \%$ of the total majority metal contents), B (24.81\%), Fe (12.61\%), Ca (4.2\%), K (19.72\%), $\mathrm{Na}(6 \cdot 14 \%), \mathrm{Mg}(2.43 \%)$ and $\mathrm{Al}(26.57 \%)$. The degree of purity at this stage is $99.96 \%$. Table 1 also presents the impurities concentrations after different purification stages. Results show that after the first thermal annealing followed

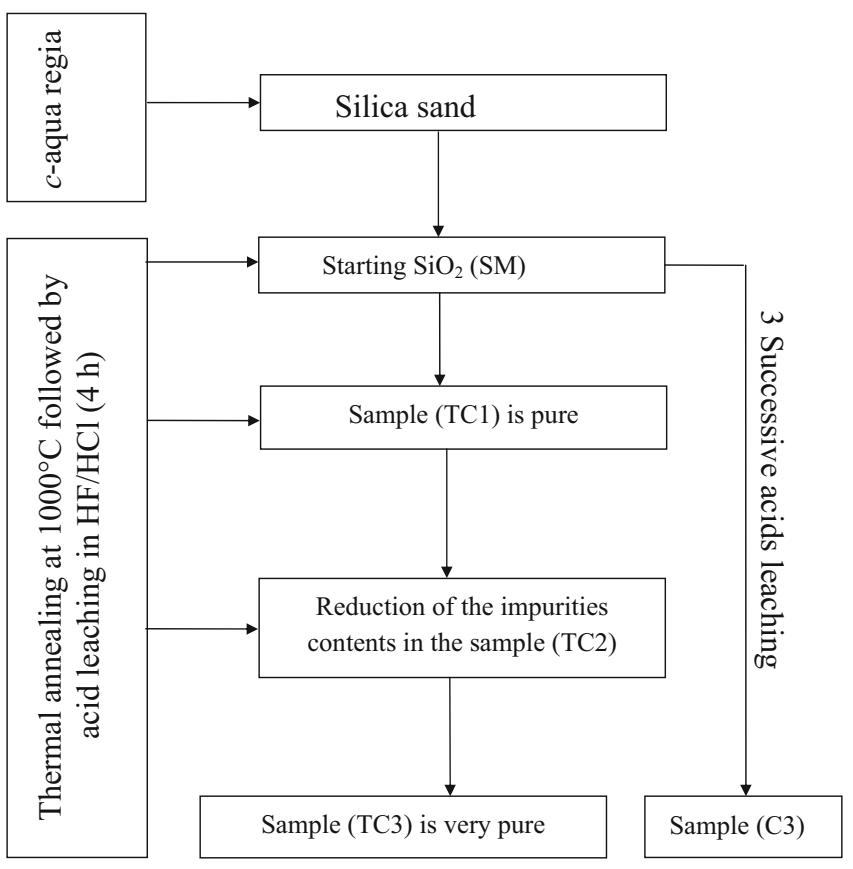

Figure 1. Scheme followed for silica purification by acid leaching and thermochemical methods. by chemical etching of the surface of silica (sample TC1), the amount of majority impurities are largely reduced. The removal of impurities is more efficient in this stage for $\mathrm{K}$, which was almost completely eliminated from the material and for $\mathrm{Al}$ which is reduced from 632 to 80 ppmw. After the second purification step (sample TC2), we observe a supplementary decrease in the undesirable impurities especially for boron, for which the concentration decreases from 410 to 164 ppmw. After the last purification step (sample TC3), the boron concentration is reduced to about half compared to the precedent sample and relatively slight reduction for other elements are observed. The effect of successive thermal annealing and acid cleaning on the total amount of impurities compared to the untreated silica are presented in figure 2 . It is clearly shown from this figure that our purification process is very efficient in the removal of undesirable impurities from silica. This process leads to a reduction of about six orders of magnitude of the total amount of impurities present in silica, which results in an improvement of the material purity from 99.76 to $99.96 \%$. Best results of the thermo-chemical purification method are presented in figure 3 , that gives a comparison between impurities concentrations in the starting silica (SM) and after three thermochemical purification stages (TC3).

To show the importance of the thermal annealing in the impurities removal, a sample that was subjected to three

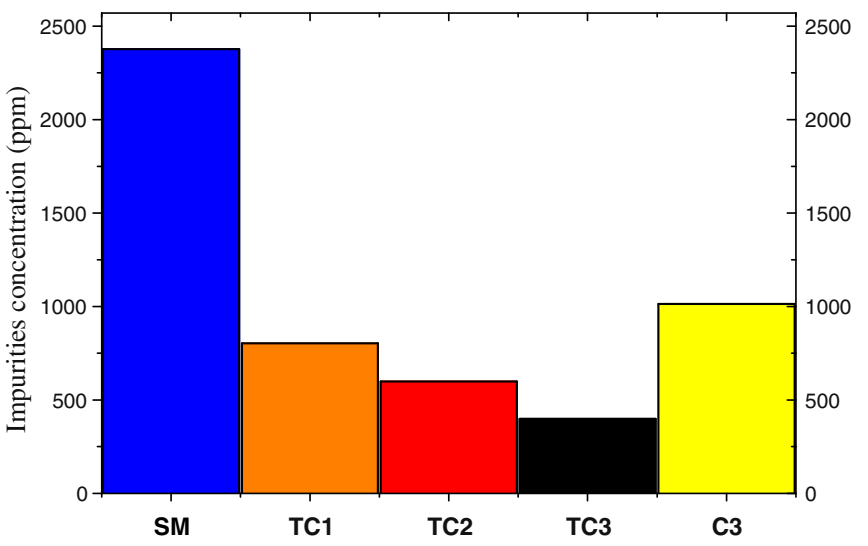

Figure 2. Evolution of total impurities contents in starting silica (SM), after different thermochemical purification stages (TC1, TC2 and TC3) and after three successive acids leaching (C3).

Table 1. Concentrations (ppmw) of impurities present in untreated silica and after different purification stages.

\begin{tabular}{|c|c|c|c|c|c|c|c|c|c|c|c|c|c|c|}
\hline \multirow[b]{2}{*}{ Sample } & \multicolumn{12}{|c|}{ Impurity concentration (ppmw) } & \multirow[b]{2}{*}{ Total } & \multirow[b]{2}{*}{$\mathrm{SiO}_{2}(\%)$} \\
\hline & $\mathrm{P}$ & B & $\mathrm{Fe}$ & $\mathrm{Ca}$ & $\mathrm{K}$ & $\mathrm{Na}$ & $\mathrm{Mg}$ & $\mathrm{Al}$ & $\mathrm{Zn}$ & $\mathrm{Ni}$ & $\mathrm{Cu}$ & $\mathrm{Cd}$ & & \\
\hline SM & 83 & 590 & 300 & 100 & 469 & 146 & $57 \cdot 9$ & 632 & $<0 \cdot 1$ & $<0 \cdot 1$ & $<0 \cdot 1$ & $<0 \cdot 1$ & $2377 \cdot 9$ & $99 \cdot 76$ \\
\hline $\mathrm{TC} 1$ & 24 & 410 & 39 & 88 & $<0 \cdot 1$ & 121 & $40 \cdot 7$ & 80 & $<0 \cdot 1$ & $<0 \cdot 1$ & $<0 \cdot 1$ & $<0 \cdot 1$ & $802 \cdot 7$ & 99.919 \\
\hline $\mathrm{TC} 2$ & 26 & 164 & 28 & 107 & $<0 \cdot 1$ & 126 & 64 & 84 & $<0 \cdot 1$ & $<0 \cdot 1$ & $<0 \cdot 1$ & $<0 \cdot 1$ & 599 & 99.94 \\
\hline TC3 & 22 & 81 & 23 & 61 & $<0.1$ & 110 & 29 & 73 & $<0 \cdot 1$ & $<0 \cdot 1$ & $<0 \cdot 1$ & $<0 \cdot 1$ & 399 & 99.96 \\
\hline$\eta(\%)$ & $73 \cdot 5$ & 86 & 92 & 39 & 99.97 & 25 & 49.9 & $88 \cdot 5$ & - & - & - & - & $83 \cdot 22$ & - \\
\hline
\end{tabular}


successive acid leaching processes (C3) is compared to the sample TC3 which was obtained after three purification stages. Each one is composed of thermal annealing followed by acid leaching. The obtained results are presented in table 2. Results show that with thermal annealing the purification process is more efficient. A more important reduction in the impurities concentration is obtained when the purification is carried out with thermal annealing and acid leaching. This difference between the two processes is due to the impurities diffusion from the volume of silica grains to their surface, during thermal annealing, where they will be localized and removed during acid leaching. The impurities diffusion can be attributed to two phenomena. The first phenomenon is the impurities diffusion due to the gradient of concentration caused by chemical cleaning. The second is due to the porous surface of silica obtained after chemical cleaning as shown in figure 4. This behaviour was also observed in silicon when it is thermally annealed, under controlled atmosphere, after the formation of a porous layer on both sides of the substrate (Khedher et al 2002; Hajji et al 2007).

Among the most undesirable impurities present in silica intended for the production of silicon are boron (B), phosphorus $(\mathrm{P})$ and iron $(\mathrm{Fe})$. These impurities largely affect electrical properties of the produced silicon. Figure 5 displays evolution of the concentration of these three impurities before and after different purification treatments. Results show that for the chemical purification (sample C3), the impurities concentrations are reduced to about half after

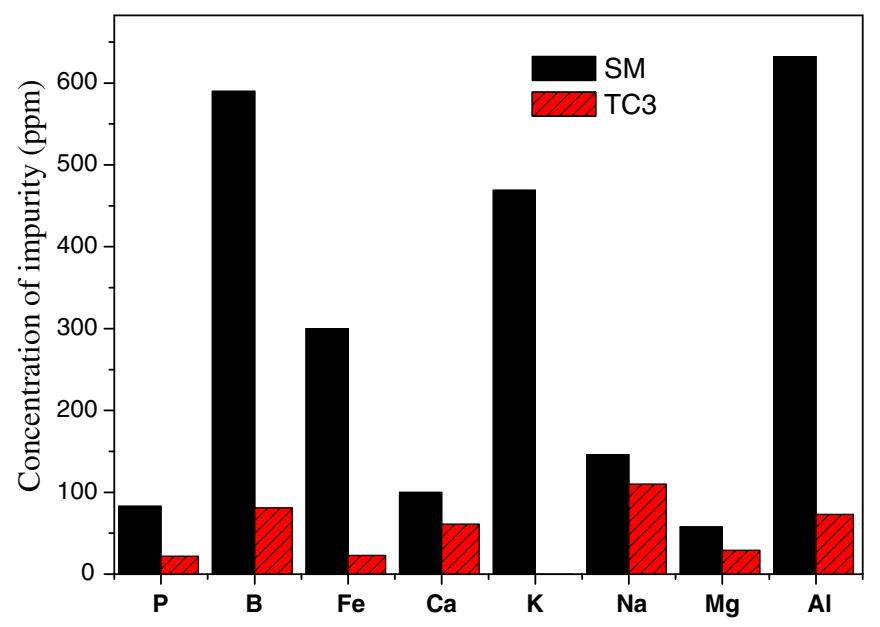

Figure 3. Impurity concentration of starting silica (SM) and after three thermochemical purification stages (TC3). three-acid leaching. On the other hand, if the purification is carried out with thermal annealing, an important reduction in the concentrations of $\mathrm{Fe}$ and $\mathrm{P}$ is observed until the first stage and further stages slightly affect these concentrations. This is not the case for boron in which the concentration is continuously reduced during different thermochemical purification stages.

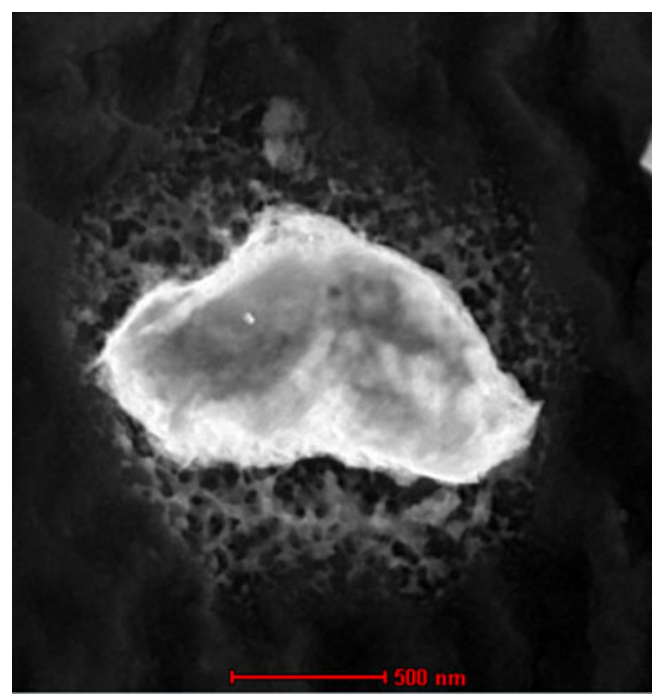

(a)

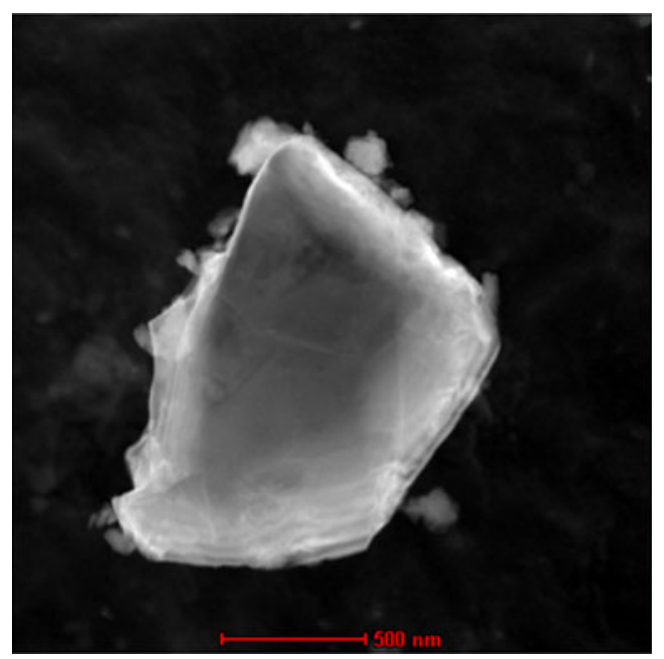

(b)

Figure 4. TEM images before purification (a) and after third thermochemical purification stage (b).

Table 2. Comparison between silica metal contents after three acids leaching and after three thermochemical purification stages.

\begin{tabular}{|c|c|c|c|c|c|c|c|c|c|c|}
\hline \multirow[b]{2}{*}{ Sample } & \multicolumn{8}{|c|}{ Impurities concentrations (ppmw) } & \multirow[b]{2}{*}{ Total } & \multirow[b]{2}{*}{$\mathrm{SiO}_{2}(\%)$} \\
\hline & $\mathrm{P}$ & B & $\mathrm{Fe}$ & $\mathrm{Ca}$ & $\mathrm{K}$ & $\mathrm{Na}$ & $\mathrm{Mg}$ & $\mathrm{Al}$ & & \\
\hline $\mathrm{C} 3$ & 50 & 300 & 153 & 184 & $<0 \cdot 1$ & 170 & 80 & 77 & 1014 & $99 \cdot 898$ \\
\hline TC3 & 22 & 81 & 23 & 61 & $<0 \cdot 1$ & 110 & 29 & 73 & 399 & 99.96 \\
\hline
\end{tabular}


The purification process is evaluated by the impurity removal efficiency, $\eta$, defined as follows:

$$
\eta=\left(C_{\mathrm{i}}-C_{\mathrm{f}}\right) / C_{\mathrm{i}},
$$

where $C_{\mathrm{i}}$ and $C_{\mathrm{f}}$ are the initial and final concentrations of impurities.

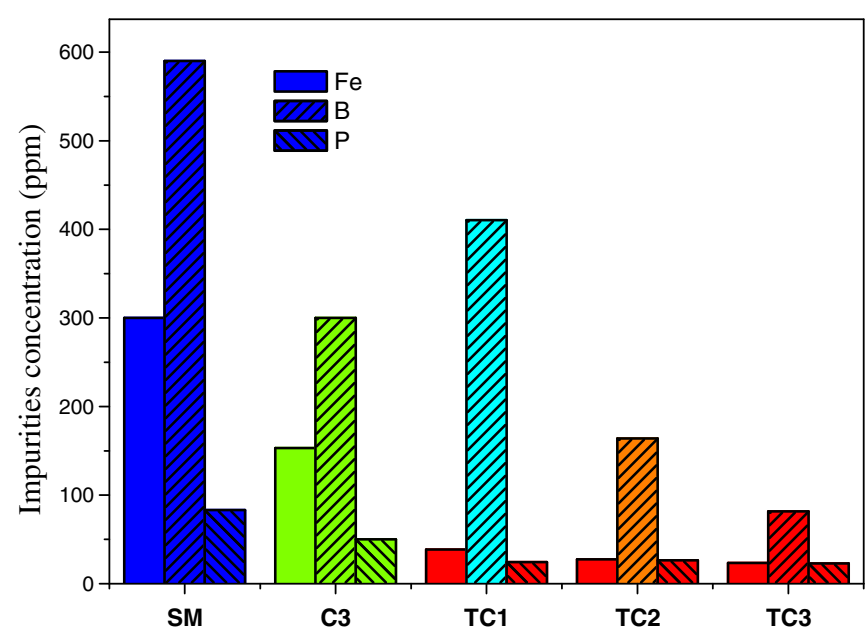

Figure 5. Evolution of iron, phosphorus and boron concentrations in starting silica and after different purification conditions.

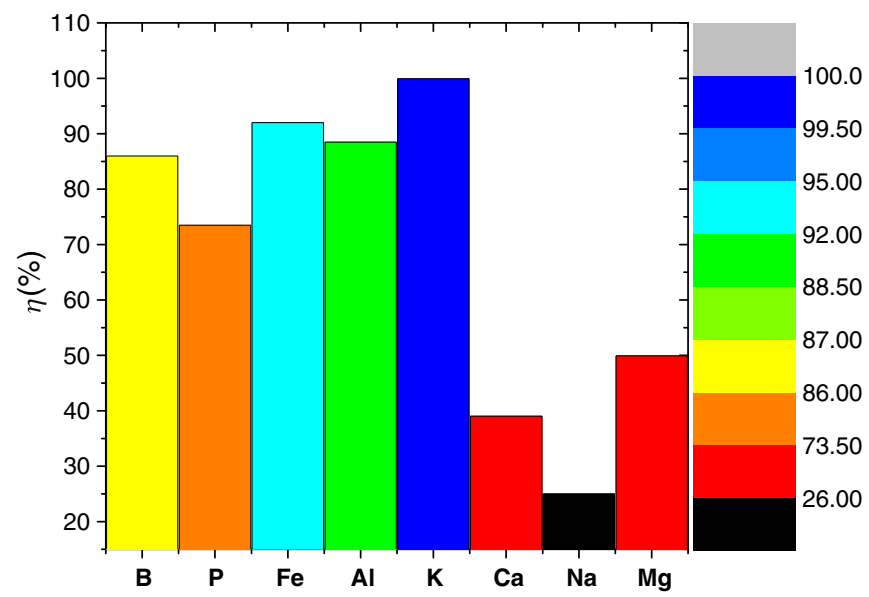

Figure 6. Removal efficiency for different impurities present in silica after three stages of thermochemical purification.
Figure 6 shows removal efficiency for the majority of impurities after third purification stage (sample TC3). As indicated in this figure, the impurities removal efficiency is higher than $70 \%$ for major part of impurities. Table 3 gives a comparison between removal efficiencies obtained after three stages of thermochemical treatment and available data from previous works using different acids leaching methods. It is clear that values of the removal efficiency for thermoschemical purification technique are higher in major part than those obtained by acid leaching techniques. For example, using a percolation leaching, Kheloufi (2009) reduced the iron contents of silica from 850 to $96 \mathrm{ppm}$ with a removal efficiency of $88.7 \%$. Barrett et al (2001), in their study, dealt on the effects of acid treatment on trace metal content of chromatographic silica, by treating silica in HF solution for $30 \mathrm{~min}$. They reduced the iron contents of silica from 227 to $122 \mathrm{ppm}$ with a removal efficiency of $46 \cdot 25 \%$. Lee et al (2009) by a treatment in $\mathrm{HCl} / \mathrm{HF}$ mixture $(\mathrm{HCF})$ reduced the iron contents from 604 to 262 ppm which corresponds to a removal efficiency of $56.6 \%$. It is clear from this comparison that thermochemical purification method is very efficient in the iron removal (92\%) and other metallic impurities present in silica sand. Those results make this method very interesting for production of silica intended for photovoltaic application.

\section{Conclusions}

Purification of silica has been investigated using acid leaching and a combination of thermal and chemical purifications. Impurities contents in untreated silica and purified one were determined by ICP-AES methods. The same leaching solution composed of $\mathrm{HF}(5 \%): \mathrm{HCl}(4 \%)$ with volume fraction of (1:7) was used for chemically treated silica and thermochemically treated one. The major impurities extracted from the starting silica were $\mathrm{P}, \mathrm{B}, \mathrm{Fe}, \mathrm{Ca}, \mathrm{K}, \mathrm{Na}$, $\mathrm{Mg}$ and Al. Obtained results show that the thermochemical purification technique is very efficient in the removal of the major part of impurities present in silica. Higher removal efficiencies are obtained, especially for iron (92\%), boron $(86 \%)$, phosphorus $(73.5 \%)$, potassium $(>99.97 \%)$ and aluminum $(88.5 \%)$. These results make this method very interesting for production of silica intended for photovoltaic application.

Table 3. Comparison between impurities removal efficiencies of thermochemical purification to those of other methods based on acid leaching.

\begin{tabular}{lcccccccc}
\hline & \multicolumn{8}{c}{ Removal efficiency (\%) } \\
\cline { 2 - 9 } Methods & $\mathrm{P}$ & $\mathrm{B}$ & $\mathrm{Fe}$ & $\mathrm{Ca}$ & $\mathrm{K}$ & $\mathrm{Na}$ & $\mathrm{Mg}$ & $\mathrm{Al}$ \\
\hline $\begin{array}{l}\text { Thermochemical } \\
\quad \text { treatment (TC3) }\end{array}$ & 73.5 & 86 & 92.33 & 39 & 99.97 & 25 & 49.9 & 88.5 \\
$\begin{array}{l}\text { Lee } \text { et al (2009) } \\
\text { Kheloufi (2009) }\end{array}$ & - & - & 56.6 & 25 & 88.3 & 64.32 & 55.6 & 88.8 \\
Barrett et al (2001) & - & - & 88.7 & - & - & - & - & 64.9 \\
\hline
\end{tabular}




\section{Acknowledgements}

This work was supported by the Ministry of High Education and Scientific Research, Tunisia.

\section{References}

Barrett D A, Brown V A, Waston R C, Davues M C, Shaw P N and Ritchie H J 2001 J. Chromatogr. A905 69

Farmer A D, Collings A F and Jameson G J 2000 Ultrason. Sonochem. 7243
Hajji M, Hassen M, Ezzaouia H, Selmi A and Bouchriha H 2007 Appl. Surf. Sci. 2535341

Khedher N, Hajji M, Bouaïcha M, Boujmil M F, Ezzaouia H, Bessaïs B and Bennaceur R 2002 Solid State Commun. 1237

Kheloufi A 2009 Chem. Eng. Trans. 17197

Lee K Y, Yoon Y Y, Jeong S B, Chae Y B and Ko K S (2009) J. Radioanal. Nucl. Chem. 282629

Mowla D, Karimi G and Ostadnezhad K 2008 Sep. Purif. Technol. 58419

Pires J C S, Braga A F B and Mei P R 2003 Solar Energ. Mater. Solar C. 79347

Santos I C, Goncalves A P, Silvasantos C, Almeida M, Afonso M H and Cruz M J 1990 Hydrometallurgy 23237 